Proceedings of the 32nd Annual Meeting of the Brazilian Embryo Technology Society (SBTE); Florianopólis, SC, Brazil, August 16th to 18th, 2018.

\title{
History, origin, and function of transzonal projections: the bridges of communication between the oocyte and its environment
}

\author{
Hugh J. Clarke \\ Department of Obstetrics and Gynecology, McGill University, Montréal, QC, Canada. \\ Research Institute, McGill University Health Centre, Montreal, QC, Canada.
}

\begin{abstract}
Development and differentiation of a functional oocyte that following fertilization is able to give rise to a new individual requires continuous physical contact with the supporting somatic cells of the ovarian follicle. As the oocyte is surrounded by a thick extracellular coat, termed the zona pellucida, this essential contact is mediated through thin cytoplasmic filaments known as transzonal projections (TZPs) that project from the somatic granulosa cells adjacent to the oocyte and penetrate through the zona pellucida to reach the oocyte. Gap junctions assembled where the tips of the TZPs contact the oocyte plasma membrane, and other contact-dependent signaling may also occur at these sites. Here, I describe early studies of TZPs, which were first identified in the late 19th century, discuss their similarities with classical filopodia, review their structure and function, and compare two models that could account for their origin. Possible priorities and directions for future studies close this contribution.
\end{abstract}

Keywords: communication, filopodia, follicle, granulosa cell, oocyte.

\section{Introduction}

Germ cell differentiation depends on communication with the somatic cells of the gonad, which constitute a micro-environment that provides it with essential nutrients and regulatory signals at each stage of its development (Fig. 1; El-Hayek and Clarke, 2016; Clarke, 2017a). In mammalian females, the granulosa cells of primordial follicles are thought to send signals that trigger the oocyte within to begin to grow. In growing follicles, the granulosa cells provide the oocyte with essential metabolites and send a signal that prevents the precocious initiation of meiotic maturation. Finally, during maturation, the granulosa cells provide still unidentified factors that increase protein synthesis in the germ cell. This intercellular communication must be established and maintained in the face of a daunting barrier - a thick extracellular coat, termed the zona pellucida, that surrounds the oocyte and physically separates it from the bodies of the granulosa cells. To overcome this barrier, thin cytoplasmic processes extend from the granulosa cells through the zona pellucida to the oocyte surface. These transzonal projections (TZPs) constitute the only means of contact and contact-dependent communication between the oocyte and its somatic environment and thus are indispensable for the production of an oocyte that is able to give rise to a new individual. Here, I review early studies of TZPs and cognate structures in nonmammalian species, describe their nature and function, discuss different models that may explain their origin, and conclude with questions for future study.

\section{Discovery and description of TZPs}

The first recorded descriptions of TZPs date from the late 19th century (Fig. 2A), where they were identified using light microscopy as birefringent channels in the zona pellucida (Hadek, 1965). Their probable role in nourishing the growing oocyte was immediately recognized and several potential mechanisms were proposed, including that they poured their contents into channels in the zona pellucida that presumably conducted them to the oocyte; that they established a cytoplasmic continuum with the egg thereby producing a giant multinucleate cell; and that they made contact with oocyte surface but the plasma membranes of the two cell types remained intact (Hadek, 1965). Thus, even at this relatively early stage, scarcely 50 years after the mammalian oocyte had first been observed, the mechanism and importance of interacting with its environment had been inferred.

Rapid progress in identifying and characterizing TZPs came with the development of electron microscopy. A large number of papers, notably including though not restricted to the laboratories of Everett Anderson, Keith Porter and Roberto Sotelo, established that TZPs are filamentous projections that extend from the granulosa cells immediately adjacent to the oocyte and penetrate through the entire width of the zona pellucida to reach the oocyte surface (Fig. 2B; Trujillo-Cenoz and Sotelo, 1959; Anderson and Beams, 1960; Anderson et al., 1976). There, the tip of the TZP often spreads to form a bulbous or foot-like structure that were partially enveloped (or hugged) by protrusions of the oocyte (Fig. 2C; Macaulay et al., 2014), thereby increasing the area of surface contact between the two cells. Both gap junctions, discussed in more detail below, and tight junctions are present at the sites of plasma membrane apposition (Anderson and Albertini, 1976; Gilula et al., 1978). Multiple TZPs project from a single granulosa cell - as many as 70 have been reported (Makabe et al., 2006) - apparently originating from one or a small number of central hubs or foci. TZPs have been described in a wide range of mammals (De Smedt and Szollosi, 1991; De Lesegno et al., 2008). In primates, TZPs have been identified that project deep 
into the oocyte, reaching even as far as the nucleus (Hope, 1965; Motta et al., 1994; Makabe et al., 2006). Studies such as these unequivocally established the nature of the germ line-soma interaction.

Inside the TZPs, the early studies revealed long filamentous striations running parallel to its axis. In addition, organelles such as mitochondria were also found along the shaft or at the base of TZPs, although what fraction of TZPs that contained such structures was generally not reported and would have been difficult to determine using electron microscopy. Between the tip of the TZP and the oocyte plasma membrane, extracellular vesicles can sometimes also be seen (Macaulay et al., 2014). Although the fraction of TZPs that are associated with vesicles is not known, this identifies a potential mechanism by which large cargo including organelles might be transferred from the granulosa cells to the oocyte.

Oocytes of non-mammalian species are also enclosed by an extracellular coat, often termed a vitelline membrane (Fig. 2D). Electron microscopy has revealed microfilament-rich processes emanating from the follicle cells that traverse the vitelline membrane to reach the oocyte surface in organisms including frog, newt, chicken and starfish (Hope et al., 1963; Perry et al., 1978; Schroeder, 1981; Browne and Werner, 1984). As in mammals, they frequently terminate as bulbous swellings that occupy pouches in the oocyte surface and gap junctions can be seen where the two membranes are closely apposed. An intriguing exception to this pattern is the zebrafish, in which both the follicle cell processes and long microvilli extending from the oocyte pass through pores in the vitelline envelope to enable direct cell-cell contact. Moreover, the oocyte microvilli appear to play a more important role in mediating the contact (Kessel et al., 1985). These observations show that the principle of germ line-somatic contact through filamentous projections is highly conserved evolutionarily.

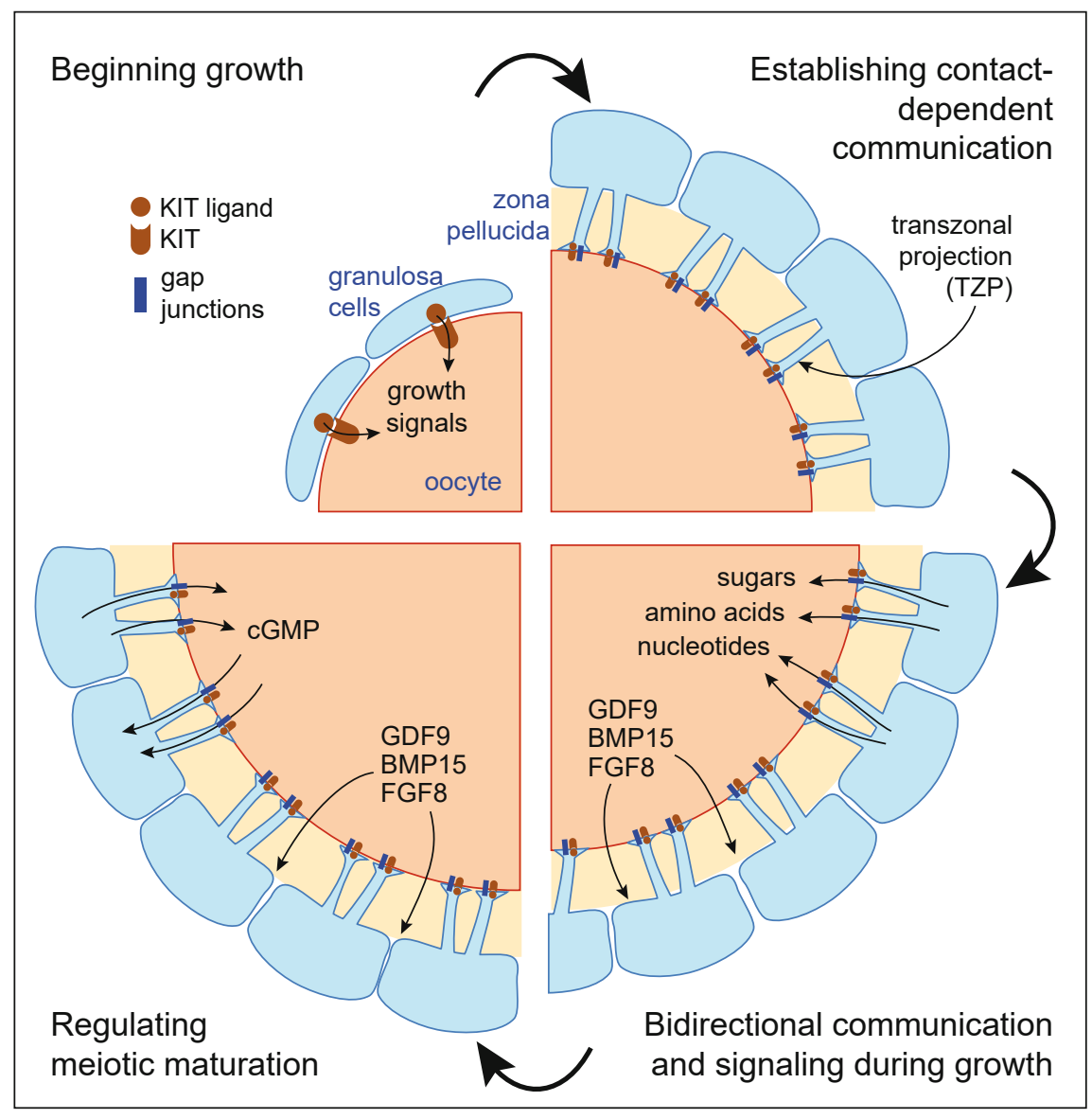

Figure 1. Communication with the somatic environment regulates all aspects of oocyte development. Clockwise from upper left: KIT ligand produced by the granulosa cells, which activates the KIT receptor on the oocyte plasma membrane, is thought to initiate growth of oocytes within primordial follicles. As the growing oocyte elaborates the zona pellucida, separating it from the bodies of the granulosa cells, the two cell types retain contact via transzonal projections (TZPs) that traverse the extracellular coat. Gap junctions, and potentially membrane-associated KIT ligand, are present where the tips of the TZPs contact the oocyte plasma membrane. The gap junctions permit the granulosa cells to transfer small molecules $(<1 \mathrm{kDa})$ to the growing oocyte. In a complementary manner, the oocyte secretes soluble growth factors that promote metabolic activity and differentiation of the granulosa cells. As oocytes reach full-size, cGMP produced by the granulosa cells is transferred to the oocyte where it prevents meiotic maturation. Conversely, maturation is initiated when cGMP levels in the granulosa cells fall so that cGMP returns to them from the oocyte, thus causing the cGMP level in the oocyte to fall. See text for further details. 


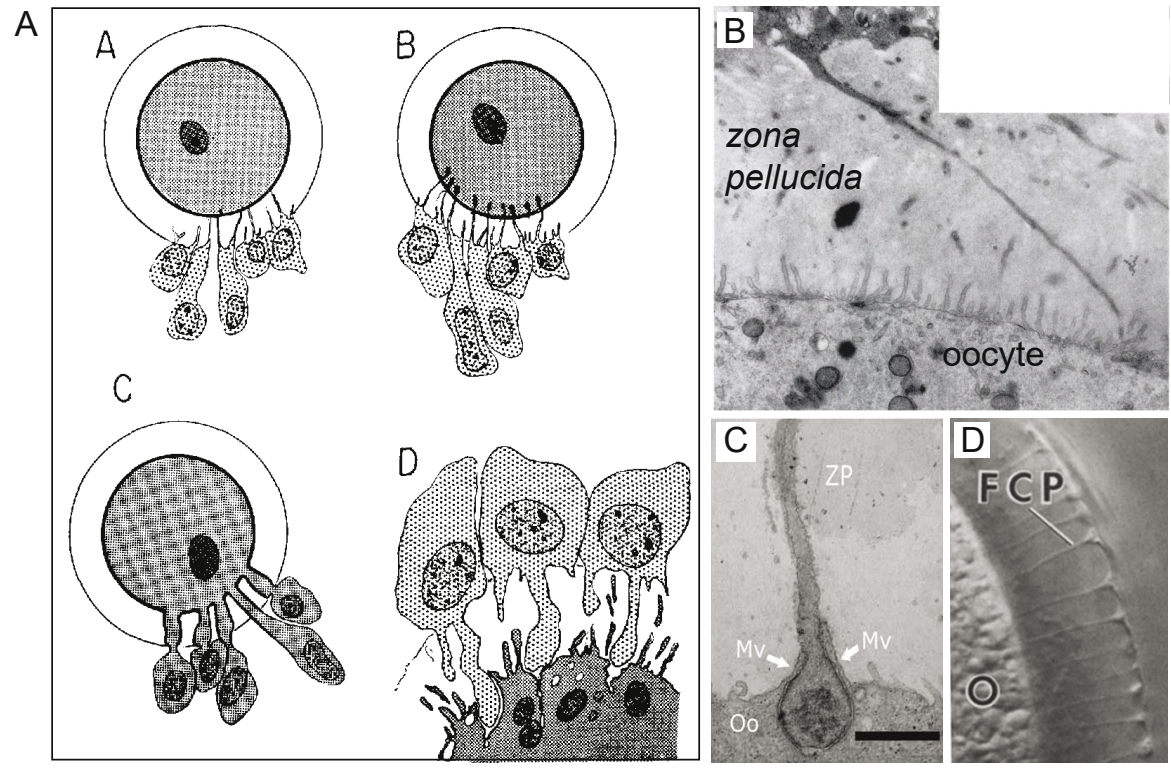

Figure 2. Identification of TZPs. A) Early depictions of TZPs and their relationship with the oocyte as described in (Hadek, 1965). Please see this review for citations of the original manuscripts. Nagel (1888, panel A) suggested that contents of the granulosa cells travel through channels within the zona pellucida and are then poured into the perivitelline space. Mjassojedoff (1923, panel B) proposed that the TZPs terminate within the oocyte. Duryee (1954, panel C) concluded that there is likely cytoplasmic continuity between the oocyte and granulosa cells. Panel D shows the author's interpretation, which essentially matches our current understanding. Reproduced with permission. B) Electron micrograph traces a TZP from its origin at the granulosa cell to the surface of the oocyte. Many microvilli can be seen at the oocyte surface. Reproduced with permission from (Zamboni, 1974). C) TZPs tips frequently become embedded in pockets at the oocyte surface and partially enveloped by protrusions of the oocyte membrane. Reproduced with permission from (Macaulay et al., 2014). D) Follicle cell processes (FCP) traverse the vitelline membrane of non-mammalian oocytes - in this vase the starfish - to reach the cell surface. Reproduced with permission from (Schroeder, 1981).

\section{Structure of TZPs}

Our understanding of TZPs took another leap forward with the advent of confocal microscopy, which provided both improved resolution and, compared to traditional fluorescence microscopy, the ability to image optical sections within the large granulosa cell-oocyte complex. Studies by David Albertini and colleagues, as well as other groups, established that many TZPs contained a backbone of actin (Fig. 3A; Albertini and Rider, 1994; Albertini et al., 2001; Barrett et al., 2010; Li and Albertini, 2013; Macaulay et al., 2014; McGinnis and Kinsey, 2015; El-Hayek et al., 2018). This anatomical feature together with their size suggests that TZPs are a type of filopodium. In support of this, we recently showed that the two types of membrane protrusions share structural elements, including DAAM1, a member of the formin family of proteins that nucleate actin assembly and fascin, which bundles actin filaments to produce stiffer fibres (El-Hayek et al., 2018). As oocytes grow and become enclosed by an increasing number of granulosa cells, corresponding to the increase in its surface area, the number of actin-rich TZPs steadily increases (El-Hayek et al., 2018).

In addition to the actin-rich TZPs, there exists also a population of TZPs possessing a core or backbone of tubulin. In mice, the tubulin-rich TZP population is very small - about two orders of magnitude less abundant than the actin-rich population (Fig. 3B; El-Hayek et al., 2018). In other mammals including primates, however, studies indicate that the tubulin-rich population may be much larger (Allworth and Albertini, 1993; Albertini and Rider, 1994). It would be valuable to quantify the tubulin-rich TZP population in non-rodent species to determine whether this reported difference reflects biological or methodological differences.

\section{Function of TZPs}

As discussed above, it was recognized as soon as TZPs were identified that they might play a key role in supporting the oocyte during its development (Anderson and Beams, 1960; Zamboni, 1974; Albertini et al., 2001). More recent studies have enabled this role to be experimentally established and molecularly defined. TZPs likely play both a nutritional and a structural role during oocyte development (Fig. 3C, D). The function of the gap junctions that become assembled where the tips of the TZPs contact the oocyte plasma membrane has been extensively investigated and is well-understood (Phillips and Dekel, 1991; SelaAbramovich et al., 2006; Kidder and Vanderhyden, 2010; Wigglesworth et al., 2013; Winterhager and Kidder, 2015). Studies using radioactive tracers showed that sugars, amino acids and nucleotides were transferred from the granulosa cells to the oocyte (Eppig, 1979; Brower and Schultz, 1982). Notably, the mouse oocyte contains small quantities of mRNAs encoding enzymes that convert glucose to pyruvate and 
of the RNA encoding the transporter that mediates uptake of extracellular alanine (Eppig et al., 2005; Sugiura et al., 2005). It should be noted that pyruvate can be transferred either through gap junctions or extracellularly. When Gja4, encoding the principal component of gap junctions in oocytes, also termed connexin 37, was knocked out in the mouse, the oocytes failed to grow to full size and were not able to undergo meiotic maturation (Simon et al., 1997; Carabatsos et al., 2000; Gittens et al., 2005). Although not formally ruling out a gap junction-independent role for GJA4, this observation highlights the essential nature of the physical communication between the growing oocyte and surrounding somatic cells.

When oocytes have reached full size, they are able to undergo meiotic maturation, but are prevented from doing so by cyclic GMP that is synthesized by the granulosa cells and transferred to the oocyte via gap junctions (Norris et al., 2009; Zhang et al., 2010; Jaffe and Egbert, 2016). Conversely, following the ovulatory release of luteinizing hormone, cGMP level rapidly falls in the granulosa cells - as a result the nucleotide flows back to the granulosa cells from the oocyte along a concentration gradient, which enables maturation to begin in the oocyte. Thus, the TZPs permit essential communication that regulates both oocyte growth and meiotic maturation.

TZPs also provide the substrate for adhesion between the oocyte and granulosa cells (Fig. 3D). Immunofluorescence studies have shown that granulosa cells express $\mathrm{N}$-cadherin including on the TZPs, whereas oocytes express mainly E-cadherin (Mora et al., 2012; Lowther et al., 2017). As well, focal adhesion kinase (FAK, also known as PTK) which participates in the formation and maturation of adherens junctions is also abundantly expressed in the granulosa cell immediately adjacent to the zona pellucida as well as the oocyte (McGinnis and Kinsey, 2015; see also below). These observations, together with the membrane localization of $\beta$-catenin, suggests that adherens junctions mediate the cell adhesion. In contrast, classical markers of desmosomes have not been detected (Mora et al., 2012), implying that this type of intercellular junction is not present. It has been speculated that the adherens junctions are present in the tubulin-rich TZPs, where the gap junctions are found in the actin-rich TZPs (Li and Albertini, 2013), indicating that the two types of TZPs perform different duties.
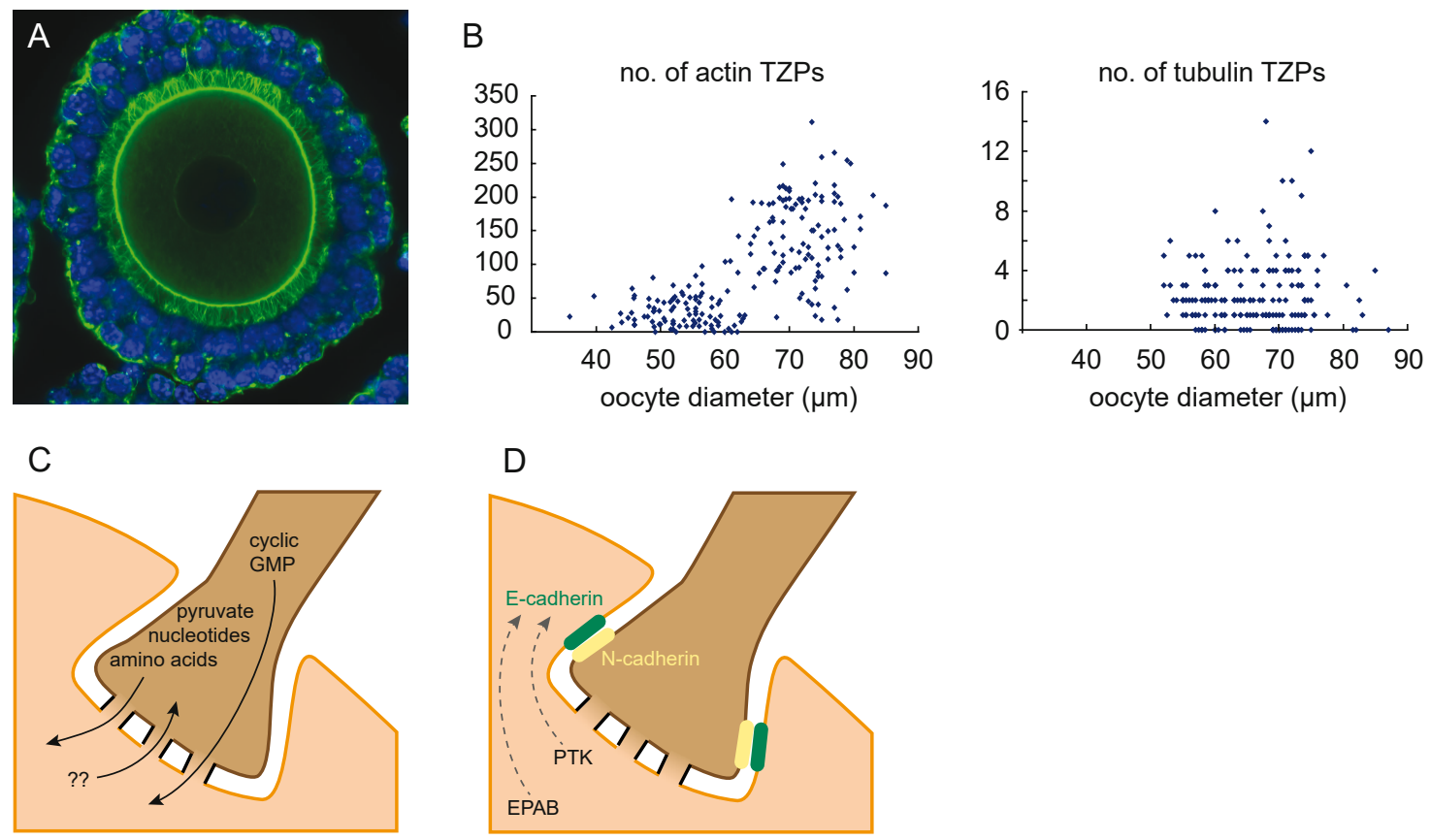

Figure 3. Characterization of TZPs. A) Confocal optical section of a granulosa cell-oocyte complex of the mouse, stained using phalloidin to label actin (green) and DRAQ5 to label DNA (blue). The oocyte in the centre is delimited by the actin-rich cortex. Two layers of granulosa cells surround it, and the dense forest of hair-like actin-rich TZPs is easily seen. Note that TZPs appear to project from all granulosa cells in the innermost layer. Reproduced with permission from (Clarke, 2017b). B) The number of actin-rich TZPs (left) increases substantially as oocytes grow. Tubulin-rich TZPs are much less numerous and do not detectably increase in number during oocyte growth. Reproduced with permission from (El-Hayek et al., 2018). C) Gap junctions become assembled where the tips of the TZPs contact the oocyte plasma membrane, and these permit the transfer of metabolites that support oocyte growth as well as of cyclic GMP that prevents initiation of meiotic maturation. Transfer from the growing oocyte to the granulosa cells is possible in principle but has not been described. Adapted with permission from (Clarke, 2017b). D) Adherens junctions maintain contact between the TZPs and the oocyte. Note that different cadherins appear to be principally responsible in the two cell types. Embryonic poly(A)-binding protein (EPAB) and the focal adhesion kinase, proline-rich tyrosine kinase 2 (PTK2), may regulate translation of the mRNA encoding E-cadherin and assembly of the adherens junction, respectively. 
Oocytes are able to grow partially when detectable gap junctional communication is blocked but not at all when they are physically separated from the granulosa cells (Eppig, 1979; Simon et al., 1997; Gittens et al., 2005; Li et al., 2007; Clarke, 2017b). This implies that granulosa cell-oocyte adhesion serves additional roles during oocyte growth, independently of permitting gap junctional coupling. Kit ligand (KL) produced by the granulosa cells can promote oocyte growth in vitro and it may do the same in vivo (Packer et al., 1994; Elvin et al., 1999; Thomas et al., 2008). The granulosa cells produce mRNAs encoding both soluble and trans-membrane forms of KL (Joyce et al., 1999; Thomas et al., 2005; Demeestere et al., 2012). If the trans-membrane form is the main bioactive form in vivo, as suggested by the in vitro data, then it must be located at the position where the TZPs contact the oocyte plasma membrane. This in turn implies that a mechanism may exist to transport newly synthesized $\mathrm{KL}$ to the tips of the TZPs. Conversely, oocyte-derived factors, including growth-differentiation factor 9 (GDF9) and bone morphogenetic protein 15 (BMP15), regulate the differentiation of the granulosa cells (Peng et al., 2013; Mottershead et al., 2015; Clarke, 2017b). Although GDF9 and BMP15 can exert known physiological functions (for example, expansion of the cumulus cell layer) when supplied in soluble form, and membrane-bound variants have not been described for either, it is intriguing to speculate whether, in vivo, they may be presented to the granulosa cells in a membraneassociated context. Such a model implies that their receptors would be enriched at the tips of the TZPs, a prediction that could be experimentally tested.

Recent studies have identified small vesicles lying between the tips of TZPs and the plasma membrane of the oocyte. In addition, transport of mRNA from the granulosa cell bodies to the tip of TZPs, as well as its transfer to the oocyte, was also observed (Macaulay et al., 2014, 2016). Based on these results, the authors suggest that, by budding off vesicles that subsequently fuse with the oocyte plasma membrane, the granulosa cells can supply the oocyte with macromolecules and organelles that are much too large to be transferred through gap junctions.

\section{Mechanism of TZP formation}

How are TZPs generated? Two mechanisms may be considered, which may be termed stretching and pushing (Fig. 4). The stretching mechanism derives from two major observations. First, in primordial follicles, there is no zona pellucida separating the oocyte and granulosa cells. After the oocytes begin to grow within primary follicles, it is deposited in discrete 'chunks' that eventually become joined together to establish an intact structure (Chiquoine, 1960; Zamboni, 1974). Second, prior to formation of the zona pellucida, intercellular junctions link the oocyte to its neighboring granulosa cells (Mora et al., 2012). Thus, it can be envisioned that the zona pellucida becomes established around pre-existing points of contact between the oocyte and granulosa cell and, as the zona pellucida thickens, pushing the granulosa cells away from the oocyte, the cytoplasm stretches to maintain the point of contact (Chiquoine, 1960; Hadek, 1965; Hope, 1965).

Although this model is attractively simple, it is not easily reconciled with several characteristics of TZPs. First, as reported by several groups based on observation and recently quantified by us, the number of TZPs increases by at least an order of magnitude during oocyte growth (Makabe et al., 2006; Li and Albertini, 2013; El-Hayek et al., 2018). Second, because the zona pellucida is laid down early during oocyte growth, many granulosa cells adjacent to the oocyte must be born after this event. According to the stretching model, these would not possess TZPs; yet TZPs appear to project from every granulosa cell that lies adjacent to the zona pellucida. Third, TZPs are destroyed when follicles are cryopreserved, yet regenerate when they are thawed and placed in culture (Barrett et al., 2010). These observations cannot easily be accommodated by the stretching model.

The pushing model holds that TZPs grow out from granulosa cells, in a manner possibly analogous to filopodial growth, and penetrate through the zona pellucida to reach the oocyte. This model could account both for the continuous increase in the number of TZPs and for their presence on all zona pellucida-adjacent granulosa cells. To test it, we combined wild-type oocytes that were fully enclosed by a zona pellucida but were completely stripped of granulosa cells with a mixture of wild-type and fluorescently tagged granulosa cells and incubated the reaggregates (El-Hayek et al., 2018). After several days, we observed fluorescently tagged TZPs projecting from tagged granulosa cells to the oocyte. These could only have been generated after we constructed the reaggregates. To test whether these projections were functional, we injected a gap junctionpermeable dye into the oocyte and observed that it spread to the neighbouring granulosa cells. These results conclusively demonstrated that granulosa cells are able to elaborate TZPs de novo that can penetrate through the zona pellucida to reach the oocyte.

Although the both theoretical and experimental evidence suggest that most TZPs are formed de novo, the two models are not entirely incompatible. It is plausible that some TZPs are derived from the points of granulosa cell-oocyte adhesion that existed prior to elaboration of the zona pellucida. In this context, it may be recalled that there exists a small population of tubulin-rich TZPs. It could be speculated that this sub-population of TZPs is generated through the stretching mechanism.

What signals trigger TZP formation by the granulosa cells? As described above, GDF9 and BMP15 produced by the oocyte regulate differentiation and gene activity in granulosa cells. Strikingly, in $\mathrm{Gdf}^{-/-}$mice, fewer TZPs are found and their structure is disorganized (Carabatsos et al., 1998). Moreover, when GDF9 was depleted in wild-type oocytes, through injection of RNAi, the granulosa cells subsequently generated fewer TZPs (El-Hayek et al., 2018). These results link GDF9 produced by the oocyte to formation of TZPs by the granulosa cells. GDF9 also up-regulates the expression 
of genes encoding DAAM1 and fascin, as well as MYO10 which promotes filopodial growth, suggesting a possible mechanism for its TZP-promoting activity (El-Hayek et al., 2018). Conversely, it has been reported that the granulosa cells of mice lacking folliclestimulating hormone (FSH) possess more TZPs than those of wild-type mice, and that administration of FSH decreases TZP number (Combelles et al., 2004). This may indicate that, once oocytes have reached full-size and become competent to develop as embryos, TZPnumber decreases by an FSH-dependent mechanism ( $\mathrm{Li}$ and Albertini, 2013).

Based on the directionality of TZP growth towards the oocyte, it is tempting to speculate that the oocyte provides chemotactic cues that guide the TZP. It is also possible, however, that there is no preferred direction for TZP growth, which instead occurs wherever it can do so unimpeded. In this context, it is noteworthy that, at the time of formation of primordial follicles, the pre-granulosa cells extend long arms that enclose the oocyte (Pepling and Spradling, 2001; Lechowska et al., 2011). While these arms are much larger than TZPs, this observation raises the possibility that (pre-) granulosa cells are predisposed to generate cytoplasmic projections including TZPs.

Once the newly elaborated TZP reaches the oocyte surface, the two plasma membranes become associated by adherens junctions, as discussed above, and gap junctions are assembled to metabolically couple the cells. The mechanisms by which these junctions are assembled, as well as whether the TZP-oocyte membrane interaction is stable or dynamic, remains unknown. When Ptk2 was deleted from growing oocytes, the number of TZPs as well as gap junctional communication were strikingly reduced. This indicates that PTK2 in the oocyte is required to establish or maintain TZP-oocyte contact (McGinnis and Kinsey, 2015). Additionally, deletion of Epab, encoding an RNA-binding protein that promotes translation, in oocytes caused a decrease in the quantity of E-cadherin in the oocyte and in the number of TZPs (Lowther et al., 2017). These results suggest that E-cadherin may be required to anchor TZPs to the oocyte plasma membrane.

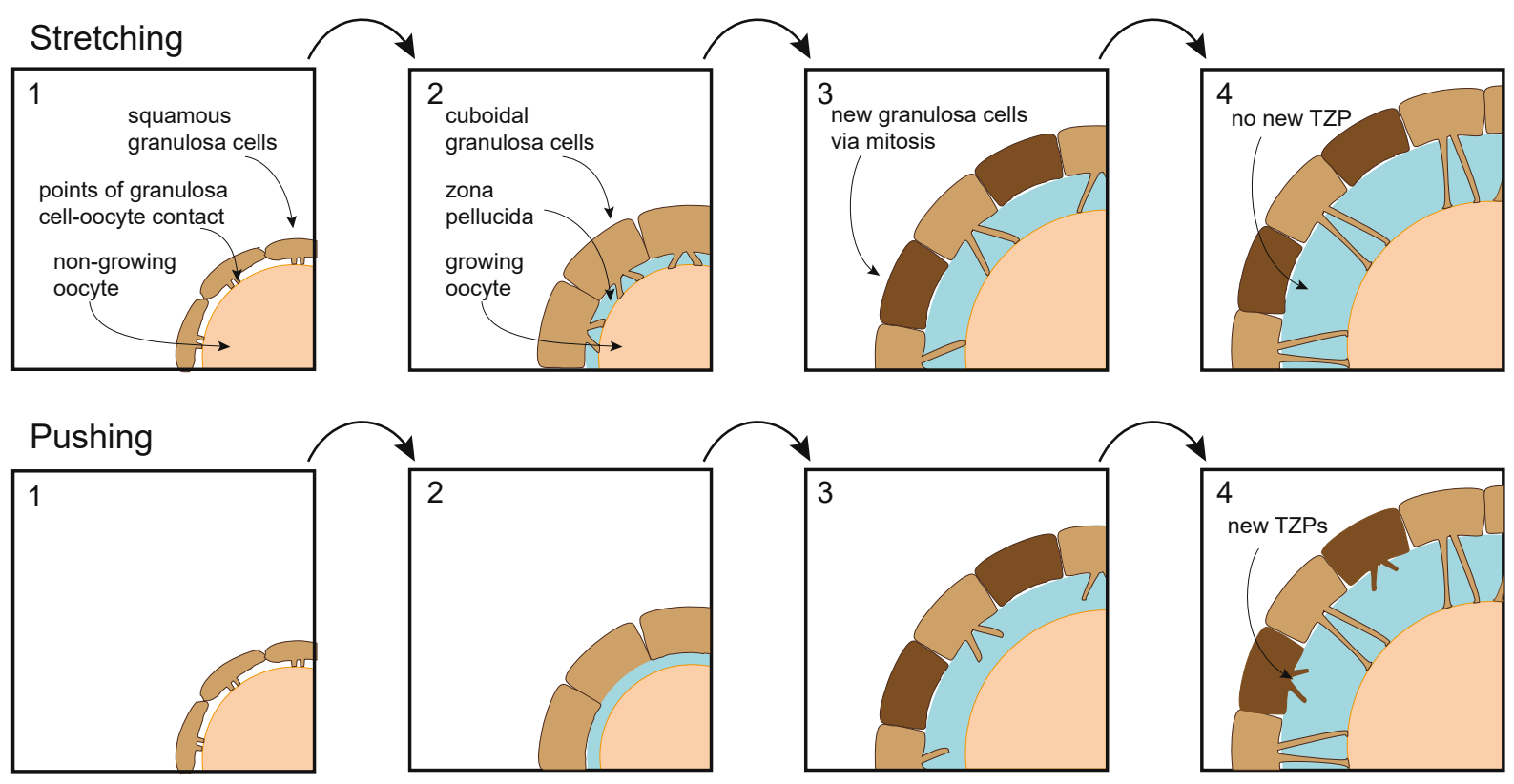

Figure 4. Models of TZP formation. Upper: stretching model. Oocytes and granulosa cells in primordial follicles establish cell junctions. When the oocyte begins to grow, it elaborates the zona pellucida. As the thickening matrix pushes the granulosa cell bodies from the oocyte, they remain attached at the original junctional connections, thus producing a stretched cytoplasmic filament. As oocytes grow, the new granulosa cells (dark brown) generated by mitosis so that the somatic cells continue to fully cover the expanding oocyte surface will not have TZPs linking them to the oocyte. Lower: pushing model. After deposition of the zona pellucida, the granulosa cells elaborate TZPs that push through the matrix to reach the oocyte surface. All granulosa cells of the innermost layer generate TZPs. The two models are not mutually exclusive.

\section{Questions for the future}

Although the basic structure and function of TZPs have long been known, the mechanisms by which these indispensable vehicles of communication between the developing oocyte and its follicular environment are produced have remained mysterious. Recent results establish that they are continuously produced by the granulosa cells surrounding growing oocytes. In view of observations that granulosa cell-oocyte communication is impaired in certain disease conditions associated with infertility (Ratchford et al., 2008) and that TZP numbers are reduced in aging females (El-Hayek et al., 2018), a better understanding of how TZPs are established and 
maintained is crucial for improving assisted reproduction in agricultural and clinical contexts Questions to be answered include:

1. Are TZPs dynamic or stable structures? If dynamic, what controls the relative rates of elaboration and retraction? Does the stability of a TZP depend on the cell-cycle state of the granulosa cell?

2. Are TZPs actively guided towards the oocyte or do they simply grow where there is space?

3. Is the zona pellucida sufficiently porous to permit growing TZPs to penetrate through it or must they digest a path?

4. Do granulosa cells stop generating TZPs once oocytes have reached full size? If so, by what mechanism?

5. Many studies have reported that TZPs are lost during meiotic maturation (Gilula et al., 1978; De Smedt and Szollosi, 1991; Phillips and Dekel, 1991; Allworth and Albertini, 1993; Suzuki et al., 2000; Barrett and Albertini, 2010). What is the mechanism?

The answers to these and other questions will not only contribute to understanding how the growing oocyte interacts with its environment but will also uncover principles governing the regulation of intercellular contact and communication.

\section{Acknowledgments}

I thank all members of the laboratory for careful experimental studies and valuable discussions. Research in my laboratory is supported by the Canadian Institutes of Health Research, the Natural Sciences and Engineering Research Council of Canada, and the National Institutes of Health (U.S.A.).

\section{References}

Albertini DF, Rider V. 1994. Patterns of intercellular connectivity in the mammalian cumulus-oocyte complex. Microsc Res Techn, 27:125-133.

Albertini DF, Combelles C, Benecchi E, Carabatsos M. 2001. Cellular basis for paracrine regulation of ovarian follicle development. Reproduction, 121:647653.

Allworth AE, Albertini DF. 1993. Meiotic maturation in cultured bovine oocytes is accompanied by remodeling of the cumulus cell cytoskeleton. Dev Biol, 158:101-112.

Anderson E, Beams HW. 1960. Cytological observations on the fine structure of the guinea pig ovary with special reference to the oogonium, primary oocyte and associated follicle cells. $J$ Ultrastruct Res, 3:432-446.

Anderson E, Albertini DF. 1976. Gap junctions between the oocyte and companion follicle cells in the mammalian ovary. J Cell Biol, 71:680-686.

Anderson E, Lee G, Letourneau R, Albertini DF, Meller SM. 1976. Cytological observations of the ovarian epithelium in mammals during the reproductive cycle. J Morphol, 150:135-165.
Barrett SL, Albertini DF. 2010. Cumulus cell contact during oocyte maturation in mice regulates meiotic spindle positioning and enhances developmental competence. J Assist Reprod Genet, 27:29-39.

Barrett SL, Shea LD, Woodruff TK. 2010. Noninvasive index of cryorecovery and growth potential for human follicles in vitro. Biol Reprod, 82:1180-1189.

Brower PT, Schultz RM. 1982. Intercellular communication between granulosa cells and mouse oocytes: existence and possible nutritional role during oocyte growth. Dev Biol, 90:144-153.

Browne CL, Werner W. 1984. Intercellular junctions between the follicle cells and oocytes of Xenopus laevis. J Exp Zool, 230:105-113.

Carabatsos MJ, Elvin J, Matzuk MM, Albertini DF. 1998. Characterization of oocyte and follicle development in growth differentiation factor-9-deficient mice. Dev Biol, 204:373-384.

Carabatsos MJ, Sellitto C, Goodenough DA, Albertini DF. 2000. Oocyte-granulosa cell heterologous gap junctions are required for the coordination of nuclear and cytoplasmic meiotic competence. Dev Biol, 226:167-179.

Chiquoine AD. 1960. The development of the zona pellucida of the mammalian ovum. Am J Anat, 106:149169.

Clarke HJ. 2017a. Control of mammalian oocyte development by interactions with the maternal follicular environment. Results Probl Cell Differ, 63:17-41.

Clarke HJ. 2017b. Regulation of germ cell development by intercellular signaling in the mammalian ovarian follicle. Wiley Interdiscip Rev Dev, 7(1). doi: 10.1002/wdev.294.

Combelles C, Carabatsos M, Kumar T, Matzuk M, Albertini D. 2004. Hormonal control of somatic cell oocyte interactions during ovarian follicle development. Mol Reprod Dev, 69:347-355.

De Lesegno CV, Reynaud K, Pechoux C, Thoumire S, Chastant-Maillard S. 2008. Ultrastructure of canine oocytes during in vivo maturation. Mol Reprod Dev, 75:115-125.

De Smedt V, Szollosi D. 1991. Cytochalasin D treatment induces meiotic resumption in follicular sheep oocytes. Mol Reprod Dev, 29:163-171.

Demeestere I, Streiff AK, Suzuki J, Al-Khabouri S, Mahrous E, Tan SL, Clarke HJ. 2012. Folliclestimulating hormone accelerates mouse oocyte development in vivo. Biol. Reprod., 87:3, 1-11. doi: 10.1095/biolreprod.112.099929.

El-Hayek S, Clarke HJ. 2016. Control of oocyte growth and development by intercellular communication within the follicular niche. Res Probl Cell Differ, 58:191-224.

El-Hayek S, Yang Q, Abbassi L, FitzHarris G, Clarke HJ. 2018. Mammalian oocytes locally remodel follicular architecture to provide the foundation for germline-soma communication. Curr Biol, 28:11241131.e3.

Elvin JA, Yan C, Wang P, Nishimori $K$, Matzuk MM. 1999. Molecular characterization of the follicle defects in the growth differentiation factor 9-deficient ovary. Mol Endocrinol, 13:1018-1034. 
Eppig JJ. 1979. A comparison between oocyte growth in coculture with granulosa cells and oocytes with granulosa cell-oocyte junctional contact maintained in vitro. J Exp Zool, 209:345-353.

Eppig JJ, Pendola FL, Wigglesworth K, Pendola JK. 2005. Mouse oocytes regulate metabolic cooperativity between granulosa cells and oocytes: amino acid transport. Biol Reprod, 73:351-357.

Gilula NB, Epstein ML, Beers WH. 1978. Cell-to-cell communication and ovulation. a study of the cumulusoocyte complex. J Cell Biol, 78:58-75.

Gittens JE, Barr KJ, Vanderhyden BC, Kidder GM. 2005. Interplay between paracrine signaling and gap junctional communication in ovarian follicles. $J$ Cell Sci, 118:113-122.

Hadek R. 1965. The structure of the mammalian egg. Int Rev Cytol, 18:29-71.

Hope J, Humphries AA, Jr., Bourne GH. 1963 Ultrastructural studies on developing oocytes of the salamander Triturus viridescens. I. The relationship between follicle cells and developing oocytes. $J$ Ultrastruct Res, 59:302-324.

Hope J. 1965. The fine structure of the developing follicle of the rhesus ovary. J Ultrastruct Res, 12:592-610.

Jaffe LA, Egbert JR. 2016. Regulation of mammalian oocyte meiosis by intercellular communication within the ovarian follicle. Ann Rev Physiol, 79:237-260.

Joyce IM, Pendola FL, Wigglesworth K, Eppig JJ. 1999. Oocyte regulation of kit ligand expression in mouse ovarian follicles. Dev Biol, 214:342-353.

Kessel RG, Tung HN, Roberts R, Beams HW. 1985 The presence and distribution of gap junctions in the oocyte-follicle cell complex of the zebrafish, Brachydanio rerio. J Submicrosc Cytol, 17:239-253.

Kidder GM, Vanderhyden BC. 2010. Bidirectional communication between oocytes and follicle cells: ensuring oocyte developmental competence. Can J Physiol Pharmacol, 88:399-413.

Lechowska A, Bilinski S, Choi Y, Shin Y, Kloc M, Rajkovic A. 2011. Premature ovarian failure in noboxdeficient mice is caused by defects in somatic cell invasion and germ cell cyst breakdown. $J$ Assist Reprod Genet, 28:583-589.

Li R, Albertini DF. 2013. The road to maturation: somatic cell interaction and self-organization of the mammalian oocyte. Nat Rev Mol Cell Biol, 14:141-152.

Li TY, Colley D, Barr KJ, Yee SP, Kidder GM. 2007. Rescue of oogenesis in Cx37-null mutant mice by oocyte-specific replacement with $\mathrm{Cx} 43$. J Cell Sci, 120:4117-4125.

Lowther KM, Favero F, Yang CR, Taylor HS, Seli E. 2017. Embryonic poly(A)-binding protein is required at the preantral stage of mouse folliculogenesis for oocytesomatic communication. Biol Reprod, 96:341-351.

Macaulay AD, Gilbert I, Caballero J, Barreto R, Fournier E, Tossou P, Sirard MA, Clarke HJ, Khandjian EW, Richard FJ, Hyttel P, Robert C. 2014. The gametic synapse: RNA transfer to the bovine oocyte. Biol Reprod, 91:90. doi: 10.1095/biolreprod.114.119867. Macaulay AD, Gilbert I, Scantland S, Fournier E, Ashkar F, Bastien A, Saadi HA, Gagne D, Sirard MA, Khandjian EW, Richard FJ, Hyttel P, Robert
C. 2016. Cumulus cell transcripts transit to the bovine oocyte in preparation for maturation. Biol Reprod, 94:16. doi: 10.1095/biolreprod.114.127571.

Makabe S, Naguro T, Stallone T. 2006. Oocytefollicle cell interactions during ovarian follicle development, as seen by high resolution scanning and transmission electron microscopy in humans. Microsc Res Techn, 69:436-449.

McGinnis LK, Kinsey WH. 2015. Role of focal adhesion kinase in oocyte-follicle communication. $\mathrm{Mol}$ Reprod Dev, 82:90-102.

Mora JM, Fenwick MA, Castle L, Baithun M, Ryder TA, Mobberley M, Carzaniga R, Franks S, Hardy K. 2012. Characterization and significance of adhesion and junction-related proteins in mouse ovarian follicles. Biol Reprod, 86:153, 1-14. doi: 10.1095/biolreprod.111.096156.

Motta P, Makabe S, Naguro T, Correr S. 1994. Oocyte follicle cells association during development of human ovarian follicle. A study by high resolution scanning and transmission electron microscopy. Arch Histol Cytol, 57:369-394.

Mottershead DG, Sugimura S, Al-Musawi SL, Li JJ, Richani D, White MA, Martin GA, Trotta AP, Ritter LJ, Shi J, Mueller TD, Harrison CA, Gilchrist RB. 2015. Cumulin, an oocyte-secreted heterodimer of the transforming growth factor-beta family, is a potent activator of granulosa cells and improves oocyte quality. J Biol Chem, 290:24007-24020.

Norris RP, Ratzan WJ, Freudzon M, Mehlmann LM, Krall J, Movsesian MA, Wang $\mathrm{H}$, Ke $\mathrm{H}$, Nikolaev VO, Jaffe LA. 2009. Cyclic GMP from the surrounding somatic cells regulates cyclic AMP and meiosis in the mouse oocyte. Development, 136:18691878.

Packer AI, Hsu YC, Besmer P, Bachvarova RF. 1994. The ligand of the c-kit receptor promotes oocyte growth. Dev Biol, 161:194-205.

Peng J, Li Q, Wigglesworth $\mathbf{K}$, Rangarajan $\mathbf{A}$, Kattamuri C, Peterson RT, Eppig JJ, Thompson TB, Matzuk MM. 2013. Growth differentiation factor 9:bone morphogenetic protein 15 heterodimers are potent regulators of ovarian functions. Proc Natl Acad Sci USA, 110:E776-785.

Pepling ME, Spradling AC. 2001. Mouse ovarian germ cell cysts undergo programmed breakdown to form primordial follicles. Dev Biol, 234:339-351.

Perry MM, Gilbert AB, Evans AJ. 1978. Electron microscope observations on the ovarian follicle of the domestic fowl during the rapid growth phase. J Anat, 125:481-497.

Phillips DM, Dekel N. 1991. Maturation of the rat cumulus-oocyte complex: structure and function. $\mathrm{Mol}$ Reprod Dev, 28:297-306.

Ratchford AM, Esguerra CR, Moley KH. 2008. Decreased oocyte-granulosa cell gap junction communication and connexin expression in a type 1 diabetic mouse model. Mol Endocrinol, 22:2643-2654.

Schroeder TE. 1981. Microfilament-mediated surface change in starfish oocytes in response to 1methyladenine: implications for identifying the pathway and receptor sites for maturation-inducing hormones. $J$ 
Cell Biol, 90:362-371.

Sela-Abramovich S, Edry I, Galiani D, Nevo N, Dekel N. 2006. Disruption of gap junctional communication within the ovarian follicle induces oocyte maturation. Endocrinology, 147:2280-2286.

Simon A, Goodenough D, Li E, Paul D. 1997. Female infertility in mice lacking connexin 37. Nature, 385:525-529.

Sugiura K, Pendola FL, Eppig JJ. 2005. Oocyte control of metabolic cooperativity between oocytes and companion granulosa cells: energy metabolism. Dev Biol, 279:20-30.

Suzuki H, Jeong BS, Yang X. 2000. Dynamic changes of cumulus-oocyte cell communication during in vitro maturation of porcine oocytes. Biol Reprod, 63:723729.

Thomas F, Ethier J, Shimasaki S, Vanderhyden B. 2005. Follicle-stimulating hormone regulates oocyte growth by modulation of expression of oocyte and granulosa cell factors. Endocrinology, 146:941-949.

Thomas FH, Ismail RS, Jiang J-Y, Vanderhyden BC. 2008. Kit ligand 2 promotes murine oocyte growth in vitro. Biol Reprod, 78:167-175.

Trujillo-Cenoz O, Sotelo JR. 1959. Relationships of the ovular surface with follicle cells and origin of the zona pellucida in rabbit oocytes. J Biophys Biochem Cytol, 5:347-350.

Wigglesworth K, Lee KB, O'Brien MJ, Peng J, Matzuk MM, Eppig JJ. 2013. Bidirectional communication between oocytes and ovarian follicular somatic cells is required for meiotic arrest of mammalian oocytes. Proc Natl Acad Sci USA, 110:E3723-3729.

Winterhager E, Kidder GM. 2015. Gap junction connexins in female reproductive organs: implications for women's reproductive health. Hum Reprod Update, 21:340-352.

Zamboni L. 1974. Fine morphology of the follicle wall and follicle cell-oocyte association. Biol Reprod, 10:125-149.

Zhang M, Su YQ, Sugiura K, Xia G, Eppig JJ. 2010. Granulosa cell ligand NPPC and its receptor NPR2 maintain meiotic arrest in mouse oocytes. Science, 330:366-369. 